\title{
SYSTEMATICITY AND VARIABILITY IN OVER TIME IL DEVELOPMENT: DEVELOPMENTAL SEQUENCES IN THE ACQUISITION OF ORDER WITHIN VPS IN ENGLISH AS A FOREIGN LANGUAGE ${ }^{1}$
}

\author{
Laura Sánchez Pérez, Universidad de Barcelona \\ Email: laura.sanchez@ub.edu
}

\begin{abstract}
The study reported here contributes to investigation of over time interlanguage development in an instructed acquisition setting. In particular, it examines the development of word order within VP in the L3 English of 45 Spanish/ Catalan bilinguals with knowledge of L2 German. The analysis of the data (factorizing procedure, distributional analysis, implicational scaling) suggests that development can be sequenced into stages, though transition across stages is gradual. Moreover, development is constrained by knowledge of a non-native language previously learned (i.e., by crosslinguistic influence).

Keywords: developmental sequence, stages, third language acquisition, crosslinguistic influence, L3 English, L2 German, interlanguage development, age, implicational scaling.

Título en español: Sistematicidad y Variabilidad en el desarrollo de la interlengua a largo plazo: Secuencias de desarrollo en la adquisición del orden de palabras en el SV en Inglés como Lengua Extranjera

Resumen El estudio reportado aquí contribuye a la investigación del desarrollo de la interlengua a largo plazo en un contexto de adquisición formal. En particular, examina el desarrollo del orden de palabras en el SV en la L3 inglés de 45 aprendices bilingües Castellano/ Catalán con conocimiento previo de L2 alemán. El análisis de los datos (proceso de factorización, análisis distribucional, escala implicacional) sugiere que dicho desarrollo se puede secuenciar en estadios, aunque la transición entre estadios es gradual. Además, el desarrollo está condicionado por el conocimiento de una lengua no nativa aprendida anteriormente (es decir, influencia transversal).

Palabras clave: secuencias de desarrollo, estadios, adquisición de terceras lenguas, influencia transversal, L3 inglés, L2 alemán, desarrollo de la interlengua, edad, escala implicacional.
\end{abstract}

Date of reception: 31 May 2010

Date of acceptance: 26 August 2010 
"How can we know the dancer from the dance?" and "O chestnut tree, greater rooted blossomer, Are you the leaf, the blossom, or the bole?"

(W.B. Yeats: 1928)

With these inspiring words Ellis (2007) tries to capture the essence of one of the most important methodological cornerstones in the search for systematicity in the study of interlanguage (e.g. early works by Nemser 1971; Selinker 1972; Selinker et al. 1975). His rationalization of the dynamics of interlanguage lies on the belief that 'in recognizing variation, individuality, and contextualization on time and space, we too must not lose sight of the wood for the trees' (p. 25). In order to account for systematicity in interlanguage, different explanations have been offered in research on second language acquisition. It is to the presentation of an overview of these that we now turn.

\section{SYSTEMATICITY AND THE REPRESENTATION OF OVERTIME INTERLANGUAGE DEVELOPMENT}

Recent accounts have confronted us with conflicting explanations that attempt to give details on interlanguage development. The main reason for disagreement among researchers seems to be the discreteness or the lack thereof as characteristic aspect in the portrait of interlanguage development at different points in time. The antagonism of these theoretical stances has resulted in representations that differ across frameworks for the study of interlanguage systematicity. Some representations view interlanguage development as a linear, discrete, stepwise and non-gradual process. This is the view that informs research on 'stages' of acquisition and on information processing.

The core theoretical thought that lies beneath research of this kind is that development takes place in passing through a series of discrete stages. As a consequence, the transition from one stage to the next is a 'stepwise movement' from one set of grammatical rules to another. In other words, a linguistic form or structure that is not part of a learner's interlanguage at a given stage or point in time is present in subsequent stages. The implication of this is that the acquisition of a given form, as expressed by its 'presence' or 'absence' in the learner's interlanguage, should be understood as uncontroversial evidence of the existence of a sequence of stages in the acquisition of features in the target language. This is true irrespective of the rate of transition across stages and of the regularity in the use of these forms.

As far as transition across stages (also referred to as 'transitional constructions' by Dulay et al. 1982 and as 'restructuring' by MacLaughlin 1990 or 'restructuring continuum' by Corder 1978) and the rate of this transition are concerned, the claim is made that "there are periods of relative stability followed by shorter periods of transition within which structural changes take place", as Sharwood Smith and Truscott (2005: 222) have rightly claimed. Some examples of research on stages are morpheme acquisition order studies, especially in English as a foreign language (see Goldschneider and DeKeyser, 2001 for a comprehensive review), and stages on the acquisition of syntactic routines (e.g. Butterworth and Hatch 1978; Gass 1980; Schumann 1979; to name just a few). Well-known cases in point in the 
acquisition of German as a second language by immigrant workers are the stages found in the pioneer work of the Heidelberg Project (e.g. Dittmar 1980) and of the ZISA Project (Zweitspracherwerb italienischer (portugiesischer) und spanischer Arbeiter) by Pienemann and his associates (e.g. Clahsen and Muysken 1989). More recently, another case in point are the stages found in the French interlanguage grammar of university students (i.e. NP; VP; tense, mood and aspect; embedding) in Bartning and Schlyter (2004). In sum, the order in which free morphemes, bound morphemes and syntactic constructions are acquired is seen as a sequence of developmental stages prior to the acquisition of a target like feature. The sequential acquisition of each feature is seen as constituting a series of fixed stages.

At the other end of this dimension, research on 'continua' (also referred to as 'recreation continuum' by Dulay and Burt 1977) lies in the assumption that interlanguage development is non-linear, non-discrete and gradual. That is, this representation sees development as a matter of gradual growth along a continuum. Within this framework, the sequencing of over time interlanguage development into stages has been severely criticized. The major argument brought forward to substantiate this criticism is grounded in the contention that division into stages leaves no room for variation and presupposes an abrupt transition between stages. In the literature, such a contention has been supported by the reinterpretation of studies on the acquisition of verb raising and agreement (for example: Eubank 1994, or Vainikka and Young-Schoten 1994) and of features associated with pro-drop grammars (e.g. White 1991). Such reinterpretations seem to bring to light the co-existence of forms for a certain period of time. In this sense, two sources of variability are repeatedly mentioned in the literature. These are 'developmental optionality' (for a full discussion of the issue of 'optionality', out of the scope of this paper, the reader is addresed to Sorace 2000) and variability induced by the native language of second language learners (Ellis 1989, 1994; Gass 1980; Kormos 2007; Lightbown 1983; Sharwood Smith 2004) or by an "L1 and other languages (L2s)" (Sharwood Smith and Truscott, 2005: 233).

A second major criticism is the apparent randomness in the border lines delimiting stages. Rather than neglecting the existence of stages, what is put into question is the use of a 'categorical' criterion in the establishment of developmental stages. Instead, stages are determined by the frequency with which absolute forms or structures are used at a given point in interlanguage development. In other words, interlanguage development takes place not as a 'stepwise' movement or as a sudden abandonment of one set of rules in favour of another one, but as a gradual growth in frequency of use of each structural solution. Randomness is causally related to decisions made by the researcher, as for example those regarding a cutting-point in accuracy percentages.

The term 'stage' has often been equated with 'mastery' rather than with 'acquisition'. As such, it has been used to refer to the order in which linguistic structures are mastered, rather than to the order in which they first appear in the learner's interlanguage. The question of structure mastery is at present considered one of the most important methodological flaws in the study of overtime interlanguage development, irrespective of the approach or the theoretical framework adopted. In their reanalysis of Vainikka and Young-Scholten's data

\footnotetext{
2 Optionality in early grammars is associated to the no operability of syntactic rules constraining grammar. Contrastingly, optionality in advanced grammars is said to be 'Residual'.
} 
(1994), Sharwood Smith and Truscott (2005) draw attention to the unreliability of using accuracy percentages as an acquisition criterion to establish a hierarchy in the acquisition of forms or structures. Pallotti (2007) brings this reanalysis a step beyond and surveys the differences in percentages that have been used in various studies. In addition to the $60 \%$ in the aforementioned study by Vainikka and Young-Scholten, he adds a 75\% in Ellis (1989), an $80 \%$ in Andersen (1978), and a 90\% in Dulay and Burt (1974) and in Bahns (1983).

An intermediate solution that makes an effort to integrate movement from one structural solution to another and co-existence of different solutions into a single whole is proposed within the MOGUL (Modular On-line Growth and Use of Language) framework. The MOGUL was developed in Sharwood Smith (2004) and Truscott and Sharwood Smith (2004), with a special interest in language processing. Its actual application to the study of interlanguage development, though, comes from their insightful discussion in Sharwood Smith and Truscott (2005). It is in this latter work where they point at the fact that 'grammatical development can be seen in both ways, as stage-by-stage and gradual' (p. 211), and use this reasoning to reconcile 'stages' and 'continua'. This intermediate position tries to 'preserve the essence of successful discrete theories while introducing into them the necessary elements of continuity and [...] optionality' (p. 230).

The main underlying assumption in this framework is that a strong relationship holds between grammatical development and 'activation level', defined here as the process operating on items stored in syntactic working memory and competition. As a result, growth is seen as gradual in that 'development consists of the gradual raising of activation levels' ( $p$. 236), but it still retains the 'stage-like' spirit typical of over time interlanguage development because development proceeds in steps. At the same time, this explains variability due to developmental optionality in terms of a more or less fleety competition between stonger and weaker activated forms. Last but not least, this framework takes for granted that the period of co-existence between forms might cover long time intervals, and that there may even be periods where neither the L1 nor the L2 are unmistakably assertive.

Further explanations for over-time interlanguage development are offered in the theories of Emergentism and Dynamic Systems. Emergentism is a probabilistic interdisciplinary theory that views development as emergence of structures in relation to their earliest systematic and productive uses. It informs SLA research within frameworks such as connectionism (e.g. Elman et al. 1996) or the competition model (e.g. MacWhinney 1997). The main postulate of the Dynamic Systems Theory (e.g. Larsen-Freeman 1997) is that language acquisition is a complex process, and it stresses the synchronic and diachronic uses of language along with the fact that different linguistic subsystems are instrinsically linked. It informs cognitive approaches, and it has been extended to research on the acquisition of a third or additional language (Herdina and Jessner 2002). The relevance of this theory to the present introduction is its overt focus on change over time.

\section{THE STUDY}

The present study adds to this line of investigation by adding a third language to the equation. It is conceived of as an attempt to contribute to current debate on the representation of interlanguage development. To do so, the development of a selected feature in the 
realm of syntax will be explored over time in data from pre- and postpubertal learners with limited exposure to the target language (L3 English). Specifically, the targeted linguistic feature is order within VP (i.e, the position of the verb in the verb phrase) in main declarative clauses.

\subsection{Research Questions}

The exact questions that guide our exploration of interlanguage systematicity in the acquisition of the position of the verb in verb phrases in English as a third language address two issues. The first research question aims to ascertain whether development can be sequenced into stages. The second research question is put forward on the condition that some systematicity can be found, and that at least some regularities can be identified on the basis of careful observation. Hence, it asks whether the transition from one stage to the next is (or not) smooth.

RQ1: In English as a third language, can the acquisition of order within VP in main declarative clauses be sequenced into stages?

If so,

RQ2: Is the transition from one stage to the next smooth?

\subsection{Hypotheses}

The present study is exploratory and does not set out to test any specific hypothesis. However, in the assumption that the answer to the first research question is affirmative, two mutually exclusive predictions can be made for the second research question. The analysis of the data will allow us to validate one and invalidate the other, and in so doing, to find out which theoretical framework (from those reviewed in Section 1) can better account for the overtime interlanguage development of the targeted linguistic feature. Our hypotheses for RQ2 went as follows:

H1: The transition from one stage to the next is 'stepwise'

$\mathrm{H} 2$ : The transition from one stage to the next is 'gradual'

\subsection{Participants}

In order to answer the research questions and validate the hypotheses presented above, the study relied on data coming from 45 learners of English as a foreign language who were bilingual in Spanish and Catalan to different extents and had prior knowledge of German. These learners attended a school in Barcelona where Spanish and Catalan (their native languages), were taught as official languages in the autonomous community of Catalonia. German as a second language in a context of partial immersion and English as a foreign language were taught as well. These learners had received instruction in German since they entered school. The input they received in this language resulted from a combination of formal exposure and occasionally also from naturalistic exposure in the form of short 
stays abroad. Yet, English as a subject was not introduced in their school curriculum until Grade 4, when learners were 9-10 years old.

\section{METHODOLOGY}

\subsection{Instruments}

The elicitation technique used in data collection was a Story Telling Task. The series of pictures used in the story is part of the battery of tests used in the BAF Project, and it is known as 'The Dog Story' (See 'Appendix'). The data collected were codified following the conventions of the CHAT sub-programme in CHILDES (Child Language Exchange System), and it is an integral part of the BELC $^{3}$ corpus. In the volume edited by Muñoz (2006), where the author presents the project and its main findings, the plot of the story is described as follows: "there are two main protagonists, a boy and a girl, who are getting ready for a picnic; a secondary character, their mother; and a character that disappears and later reappears, a dog that gets into the food basket and eats the children's sandwiches" (p. 21).

\subsection{Procedure}

The study was cross-sectional, included different-aged learners at time-of-testing (Grades 5,7 and 9) and hence represented a range of proficiencies (Larsen-Freeman and Long 1991: 13) in English, the target language under inspection. We controlled for the independent variables 'Intensity of Instruction' (1 hour a week) and 'Age of Onset' (i.e., Grade 4 for fifth graders, and Grade 6 for seventh and ninth graders). Learners were classified according to age at time-of-testing into three groups. The first one (G5) comprised 15 learners (mean age: 10.9) at the time of data collection. At that time, the mean ages of learners in the second (G7, $n=13)$ and third $(\mathrm{G} 9, n=18)$ groups were 12.9 and 14.9, respectively.

\subsection{Analysis}

\subsubsection{Background Languages Description}

Before presenting the methodology used in the analysis of the data, it is necessary to summarize the main typological differences among the languages in our study. From the point of view of 'headedness' (Beck 1998; Hopp 2003), the native languages of our bilingual learners (Spanish and Catalan) and the target language of the study (English) are similar in that they are head-initial languages. That is to say, in all of them the complements of the verb are post-verbal (i.e., they are placed after the head of the verb phrase). These languages, however, differ from German in that respect as German is a head-final language.

\footnotetext{
3 The BELC Corpus (Barcelona English Language Corpus) is available online at http://talkbank.org/data/ SLA/.
}

Odisea, $n^{\circ} 11$, ISSN 1578-3820, 2010, 59-83 
Since German behaves differently in this respect and for the sake of clarity, we will briefly look at the main characteristics of verb placement in German main clauses, which is the linguistic focus of our investigation. As a consequence of verb raising, the finite verb in main clauses always appears in second position. Hence, when the first constituent is not the subject, there is inversion of subject and verb. The application of this rule ('INV') is illustrated in (2) below.

(1) Peter schreibt gerade einen Brief

* Peter writes ${ }^{4}$ at this moment a letter

(Peter is writing a letter at this moment)

(2) Gerade schreibt Peter einen Brief

* At this moment writes Peter a letter

(At this moment Peter is writing a letter)

A second rule operative in main clauses is 'SEP' ('Verb Separation' or 'Split Verb'5), that is, the separation of finite and non-finite forms in complex verb constructions. The following example illustrates this rule:

(3) Peter hat gerade einen Brief geschrieben

* Peter has just a letter written

(Peter has just written a letter)

The INV rule applies to both simple verb constructions and to complex verb constructions. Hence, in some cases INV and SEP may operate simultaneously on the same verb phrase, as shown in (4):

(4) Gerade hat Peter einen Brief geschrieben

* Just has Peter a letter written

(Peter has just written a letter)

\subsubsection{Data Analysis Process}

In order to avoid any terminological or methodological confusion as regards the use of the term developmental 'sequence' in the present study, we will first define it. In the present

\footnotetext{
4 In contrast to the other languages in this study, German marks neither imperfective nor progressive (or continuous) aspect (Carrol et al. 2001; Stutterheim 2003). That is, there is no aspect that expresses the 'ongoingness' (as opposed to 'habitual') occurrence of the state or event expressed by the verb (Greenbaum and Quirk 1993; Huddleston and Pullum 2006). However, the 'in-progress' meaning in the referential view of time in this language can be expressed in the concurrent use of a present tense that is realized by verb inflection (i.e. 'Das Präsens') and the time adverb gerade.

5 The terminology used here follows that used in the ZISA Project on the acquisition of German as a second language. Nonetheless, this rule has been labeled using a different terminology in other studies. Some common alternative labels are 'Particle Rule' (Jordens 1988: 152), 'Rule of Discontinuous Verb Placement' (Clahsen 1985: 319), or 'Verb-Complement order in main clauses’ (Möhring and Meisel 2003: 300).
} 
study, sequence refers to 'overall developmental profile' (Ellis 1989: 64) on the supposition that 'L2 learners do not progress from zero knowledge of a target language rule to perfect knowledge of the rule' and that they 'progress through a series of interim or developmental stages on their way to target language competence' (p. 59). Our analysis of developmental sequences explored the dynamics of interlanguage development by proposing a rank order of positions of the verb in the VP as they first occured in the learners' interlanguage. This was done by describing interlanguage in terms of its own internal regularities irrespective of command of the targeted structure or of related errors. This criterion is a prerequisite for any unquestionable claim as regards a hierarchy of structures in their order of appearance. At the same time, it constitutes an acquisition criterion that makes it possible for the researcher to reasonably claim that a given structure has been 'acquired' (Andersen 1984; Pallotti 2007) or is in the process of being acquired before another one. Two immediate implications of this criterion are its facilitative effects on future replication and confirmation or rejection of empirical findings.

Bearing in mind these considerations, we now proceed to present the criteria we used in identifying the order in which the targeted structures in our study appeared in the L3 English interlanguage of our learners. By so doing, we confidently established regular distributional patterns. In order to determine the first occurrence of these structures, we used a three-step procedure that allowed us to grasp the systematicity of individual and group production, and that is roughly based on the methodology employed in the ZISA Project. It is of crucial importance here to remember that although English and Spanish display the same surface structure in the linguistic environment examined here, in German main clauses contrasting surface orders result from the application of different rules depending on the constituent that occupies the first position (see Section 3.3).

The first step in our analysis was factorising the linguistic environments that our empirically relevant context embraces, which will be justified in turn. The quantitative and qualitative analyses of our data were performed in the second and third phases of our three-step procedure, respectively. The notion of 'factorization' was introduced by Pienemann (1998), and it designates a process whereby certain linguistic features and/ or environments are 'factored out' of the analysis with the purpose of getting a clearer picture of the use of a given interlanguage rule: 'factorising ${ }^{6}(\ldots)$ features and the linguistic environment will allow one to trace the learner's own system of form-function mapping which may be closer to one-to-one relations earlier on in the acquisition process' (p. 159). In our study, this process consisted in excluding from the analysis: a) all linguistic environments where complex verb constructions might be affected either by the simultaneous operation of 'SEP' and 'INV', or by rules that apply to complex verb constructions in embedded clauses; and b) 'SEP with V-Complement', that is, linguistic environments where the lack of verb complementation prevented us from verifying the application or non-application of 'SEP' because the clause consisted only of two constituents (the Subject and the Verb). This entailed, for example, the exclusion from the sample of simple sentences that began with a topicalized constituent or with an adverb. Leaving aside linguistic contexts where

Emphasis in the original. 
different rules might be at work at the same time let us know which rule underlain the occurrence of a given structure.

The isolation of linguistic contexts permits the recognition of rules underlying interlanguage behaviour, because it draws up the boundaries of functional and structural contexts for the use of the targeted feature. The distributional analysis was the second step of our three-step-procedure. As the main goal of conducting this analysis was to isolate and discriminate between linguistic contexts (Pienemann 1998: 153), the division into structural domains was of outmost importance. This division was pertinent so as to determine not only which linguistic structures are used, but most importantly, the assertion whether the underlying rule corresponds to a TL rule (i.e., whether or not the order within VP is the order of the target language). Our division into structural domains is bolstered by empirical findings in earlier work that used a) the present database, and b) an additional data subset from a larger corpus (author 2007a). The initial structural domains selected here were tense and modal auxiliaries followed by a non-finite form. In view of the findings reported in author (2007a, 2007b), these were further subdivided into four structural domains (presented in figure 1). Specifically, tense as a grammatical category was investigated by looking at auxiliaries in secondary tenses, that is, those that mark distinction by means of an auxiliary. Mood here is understood: a) as a grammatical form that expresses the semantic category of 'modality' in lexical means (that is, by using modal auxiliaries) and b) as a grammatical form that expresses futurity ${ }^{7}$. This distinction in mood is reflected in Structural Domains 3 and 4, respectively. In other words, our analysis does not take into account tense realized by verb inflection and mood defined as the grammaticalization of modality by means of inflectional morphology. The third step in our analysis involved turning the quantitative distributional analysis into a qualitative implicational scaling ${ }^{8}$ (Andersen 1978; Bol 1995; DeCamp 1973; Guttman 1944; Platt 1977; Hyltenstam, 1977). As this regards, Andersen (1978), as discussed in Larsen-Freeman and Long (1991: 110), 'recommends the use of implicational scaling analysis as one way of displaying data with regards to variability and systematicity in SLA', In the study reported here, this analysis is conducted in order to: 1) efficiently obtain and draw a hierarchy in the use of complex verb constructions on the basis of their use in different structural domains; 2) observe the over-time development of these constructions in the interlanguage of our learners and sequence the acquisition of order within VPs.

\footnotetext{
The semantic distinction between 'modality' and 'futurity' is based on Huddleston and Pullum (2006: 56) who in spite of this distinction (the auxiliary 'will' is regarded both grammatically and semantically as a mood marker rather than a tense marker), see an 'intrinsic connection between future time and modality'.

8 The aim of this study is not to assess the applicability of implicational scaling techniques as proposed in the Processability Theory framework. Rather, this tool is used just in order to observe the order of emergence of the targeted linguistic feature in interlanguage, so that its acquisition can be sequenced into stages.

9 Emphasis added.
} 
Figure 1. Structural Domains.

1)

Declarative

Main Clause

Complex VP

$(\mathbf{A U X}+\mathrm{V}[\mathrm{nf}])$

Structural Domain 1: Tense Auxiliary + Past Participle

Structural Domain 2: Tense Auxiliary + Present Participle
2)

Declarative

Main Clause

Complex VP

(MOD + V[nf])

Structural Domain 3: Modal Auxiliary (Modality) + Infinitive

Structural Domain 4: Modal Auxiliary

(Futurity) + Infinitive

\section{RESULTS}

\subsection{Factorising and data sample}

This section opens with a few examples of the kind of data produced by our learners. Examples 5 to 8 illustrate the production of complex verb constructions in the different structural domains that make up our empirically-relevant context.

(5) The dog has eaten all the food

(6) The mother is preparing tea

(7) The must go (to) outside

(8) They will go to a camping

As we have indicated in the previous section, the relevance of the analysis of factorised environments is that they allow the researcher to observe the application of a given interlanguage rule in different contexts. The rule applied in the examples above resembles the rules that underlie Standard English in adult native speakers. In contrast to these, the structures produced in data such as that presented in 9 and 10 below elucidate that the operative rule is not characteristic of English. In particular, the underlying rule in these examples corresponds to German 'SEP'. The occurrence of these structures in our data was not anecdotic. In fact, the application of 'SEP' is productive, and it is distinctive of more than half the clauses analyzed. This high productivity is in itself one of the most important findings of the study reported here, and it will be dealt with in Section 4.2. In the following examples, the verb forms used in complex verb constructions appear in italics to illustrate the application of 'SEP' in English main clauses.

(9) *The dog has a cake eat

'The dog has eaten a cake'

(10) *They are a picnic preparing

'They are preparing a picnic' 
In accordance with the methodology used in other studies, our data sample includes clauses that lack the finite verb but a non-finite verb is placed in clause-final position, as in (11) below. It also fits in interlanguage production with malformations, no agreement, or lack of inflection (12), as well as interlanguage with mixed forms from any of the background languages (11).

(11) *The $\operatorname{dog} \theta$ sandwiches gegessen (*The dog [has] sandwiches eaten)

(12) *The dog have the sandwich eat

(*The dog has the sandwich eaten)

\subsection{DISTRIBUTIONAL ANALYSIS}

This section presents the results of the distributional analyses of systematic ordering of verb forms within complex verb phrases in the interlanguage of our learners at different points in time. Whereas each table shows the 'state' of the interlanguage at a single point in time, the evolution of structures with increasing age shows the development of interlanguage over time. In particular, in light of the fact that the underlying rule in most of the data produced by our learners was 'SEP', the distributional analyses of the interlanguage of learners at Grades 5, 7, and 9 list its occurrence in different structural domains. The results of these analyses are presented in distributional tables (1 to 3 below). In these tables learners are rank ordered along the vertical axis as a function of the order in which 'SEP' first appeared in their interlanguage. This means that the numbers are inversely proportional to accuracy in the ordering of verb forms within complex verb constructions, in the understanding that the occurring structures do not unavoidably have to coincide with the norm in the target language. In order not to come up with misleading results, it is compulsory to make an explicit distinction between the 'no-creation' of empirically relevant contexts and the 'non-occurrence' of the targeted structures in these contexts. In practical terms, this distinction was articulated by using in each structural domain a stroke (/) whenever the empirically relevant context was not created, and a minus (-) when the context was created but the structure did not occur. Whenever this structure was created, its presence was expressed in proportions which ranged from 0 . to 1 .

The results of the distributional analyses across the different age groups are now presented. In Grade $5(n=15)$ the linguistic forms associated with some of the structural domains analysed here had not emerged yet in the learners' interlanguage. This is the case of the use of modal verbs (Structural Domains ' 3 ' and ' 4 '), and of the present participle ('Structural Domain 2'). Hence, the analyses of the data in this grade are restricted to interlanguage data produced in 'Structural Domain 1', which corresponds to the use of a 'Tense Auxiliary + Past Participle' (i.e. present perfect simple). With the sole exception of one learner, the interlanguage rule underlying the occurrence of complex verb constructions in this structural domain is 'SEP'. To put it another way, only in one occasion the complements of the verb were post-verbal, as expected in head-initial languages (which is the case of English). These results suggest a strong tendency to use some structures ('SEP': 90\%) 
but not others in a given domain. In the absence of empirically relevant contexts in other structural domains, it is impossible to attest the application of 'SEP'.

Table 1. Distributional Analysis of 'SEP' in Grade 5 (10-11 years) in different Structural Domains

\begin{tabular}{|c|c|c|c|c|}
\hline PARTICIPANT & $\begin{array}{c}\text { Structural } \\
\text { Domain } \\
\text { Grade5(n=15) }\end{array}$ & $\begin{array}{c}\text { Structural } \\
\text { Domain } \\
\text { '2' }\end{array}$ & $\begin{array}{c}\text { Structural } \\
\text { Domain } \\
\text { '3 }\end{array}$ & $\begin{array}{c}\text { Structural } \\
\text { Domain } \\
\text { '4' }\end{array}$ \\
\hline 003 & 1 & $/$ & $/$ & $/$ \\
\hline 004 & 1 & $/$ & $/$ & $/$ \\
\hline 005 & 1 & $/$ & $/$ & $/$ \\
\hline 006 & 1 & $/$ & $/$ & $/$ \\
\hline 007 & 1 & $/$ & $/$ & $/$ \\
\hline 010 & 1 & $/$ & $/$ & $/$ \\
\hline 011 & 1 & $/$ & $/$ & $/$ \\
\hline 014 & 1 & $/$ & $/$ & $/$ \\
\hline 015 & 1 & $/$ & $/$ & $/$ \\
\hline 002 & $/$ & $/$ & $/$ & $/$ \\
\hline 008 & $/$ & $/$ & $/$ & $/$ \\
\hline 009 & $/$ & $/$ & $/$ & $/$ \\
\hline 012 & $/$ & $/$ & $/$ & $/$ \\
\hline 013 & $/$ & $/$ & $/$ & $/$ \\
\hline 001 & 0 & $/$ & $/$ & $/$ \\
\hline
\end{tabular}

In G7 some of the morphological forms that had not appeared yet in the interlanguage of the learners begin to emerge (Structural Domains ' 2 ' and ' 4 '), but their use is not consistent and the creation of contexts for their use is still restricted. Moreover, constructions in the domains examined here might be used in linguistic contexts that are not targeted in the present study (as for example, in embedded clauses). In this grade the use of the present continuous (and to a lesser extent, also the future simple) increases, what allows for the observation of the structures that occur in Structural Domains ' 2 ' and ' 4 ' ('Tense Auxiliary' + Present Participle' and 'Modal Auxiliary + Infinitive'). In the former, no single 'SEP' is observed; in other words, all occurrences conform to rules in Standard English in adult native speakers. In the latter, results are inconclusive because only two learners create contexts. Out of these two, one produces 'SEP' orders and the other one does not. The one who does produce 'SEP' in this structural domain also does so in 'Structural Domain 1 '. In fact, this learner creates empirically relevant contexts only in structural domains ' 1 ' and '4', and exclusively 'SEP' orders occur in these contexts. The one who does not, however, produces 'SEP' in 'Structural Domain 1'. The increase in the use of these verb tenses causes a slight fall in contexts created for 'Structural Domain 1'. In contrast to the tendency observed in G5, in G7 there is some variability in this domain, though 'SEP' is still the prevailing order ( $70 \%$ of exclusive occurrence of 'SEP', $20 \%$ or 'SEP' co-occurring with other orders, and $10 \%$ of TL orders). 
Table 2. Distributional Analysis of 'SEP' in Grade 7 (12-13 years) in different Structural Domains.

\begin{tabular}{|c|c|c|c|c|}
\hline PARTICIPANT & $\begin{array}{c}\text { Structural } \\
\text { Domain } \\
\text { Grade7 } 7(\mathrm{n}=13)\end{array}$ & $\begin{array}{c}\text { Structural } \\
\text { Domain } \\
\text { '2' }\end{array}$ & $\begin{array}{c}\text { Structural } \\
\text { Domain } \\
\text { '3' }\end{array}$ & $\begin{array}{c}\text { Structural } \\
\text { Domain } \\
\text { '4' }\end{array}$ \\
\hline 043 & 1 & $/$ & $/$ & 1 \\
\hline 037 & 1 & $/$ & $/$ & $/$ \\
\hline 041 & 1 & $/$ & $/$ & $/$ \\
\hline 047 & 1 & $/$ & $/$ & $/$ \\
\hline 038 & 1 & $/$ & $/$ & $/$ \\
\hline 044 & 1 & $/$ & $/$ & $/$ \\
\hline 042 & 1 & $/$ & $/$ & $/$ \\
\hline 035 & .50 & $/$ & $/$ & $/$ \\
\hline 036 & .50 & 0 & $/$ & $/$ \\
\hline 040 & $/$ & $/$ & $/$ & $/$ \\
\hline 046 & $/$ & $/$ & $/$ & $/$ \\
\hline 045 & $/$ & 0 & $/$ & $/$ \\
\hline 039 & 0 & 0 & $/$ & $/$ \\
\hline
\end{tabular}

In G9 there is no perceptible change in grammatical development. Nevertheless, in this grade morphological forms are used in a certainly more regular manner, and this concurs with a moderate proliferation of the number of contexts created. As far as the occurrence of complex verb constructions is concerned, no contexts are created for 'Structural Domain 3' (as in G5 and G7). That means that the linguistic forms associated with this domain (i.e. modal auxiliaries expressing factual or asserted modality) have not emerged yet in the interlanguage of these learners. The pattern in 'Structural Domain 4' is strikingly similar as in G7, and the orders in 'Structural Domain 2' show no change if compared with G7 (that is, no 'SEP' occurs as long as contexts are created) nor if compared with G5 (as in this grade no contexts were created at all). The orders in 'Structural Domain 1' show more variability. The most important remark to make in this grade is the persistence of 'SEP' (43\%), though there is a decrease if compared with G7 and G5 as seen in the percentages that 'SEP' represent in these grades. Interestingly, if we concentrate on the evolution of 'SEP' orders over-time, we find that the drop in 'SEP' from one grade to the next is more obvious in more instructed learners (20\% from G5 to G7, and $27 \%$ from G7 to G9). 
Table 3. Distributional Analysis of 'SEP' in Grade 9 (14-15 years) in different Structural Domains.

\begin{tabular}{|c|c|c|c|c|}
\hline PARTICIPANT & $\begin{array}{c}\text { Structural } \\
\text { Domain } \\
\text { Grade9(n=17) }\end{array}$ & $\begin{array}{c}\text { Structural } \\
\text { Domain } \\
\text { '2' }\end{array}$ & $\begin{array}{c}\text { Structural } \\
\text { Domain } \\
\text { '3' }\end{array}$ & $\begin{array}{c}\text { Structural } \\
\text { Domain } \\
\text { '4' }\end{array}$ \\
\hline 077 & 1 & $/$ & $/$ & 1 \\
\hline 073 & 1 & $/$ & $/$ & $/$ \\
\hline 071 & 1 & 0 & $/$ & $/$ \\
\hline 070 & .80 & 0 & $/$ & $/$ \\
\hline 067 & .25 & $/$ & $/$ & $/$ \\
\hline 068 & $/$ & $/$ & $/$ & $/$ \\
\hline 074 & $/$ & $/$ & $/$ & $/$ \\
\hline 079 & $/$ & $/$ & $/$ & $/$ \\
\hline 076 & 0 & $/$ & $/$ & $/$ \\
\hline 081 & 0 & 0 & $/$ & $/$ \\
\hline 082 & $/$ & $/$ & $/$ & $/$ \\
\hline 075 & $/$ & $/$ & $/$ & $/$ \\
\hline 078 & $/$ & $/$ & $/$ & $/$ \\
\hline 069 & $/$ & $/$ & $/$ & $/$ \\
\hline 072 & $/$ & $/$ & $/$ & $/$ \\
\hline 083 & & $/$ & $/$ & $/$ \\
\hline 084 & & $/$ & $/$ & $/$ \\
\hline
\end{tabular}

In order to furnish these results, the data obtained from the distributional analyses were treated statistically using the non-parametric Mann-Whitney U Test with a significance level set at 0.05 . This test revealed a significant difference between Grades 5 and 9 in the presence of 'SEP' orders in 'Structural Domain 1' $(\mathrm{p}=.008)$. No significant difference, though, was found in the comparisons between Grades 5 and $7(p=.129)$ or between Grades 7 and 9 ( $\mathrm{p}=.355)$ in this structural domain. The test could not be run on data in 'Structural Domain 3 ' because the dependent variable was constant (/), and in 'Structural Domain 4' no differences were found. The test was performed also on data obtained for 'Structural Domain 2', and it yielded the same results as in 'Structural Domain 1', namely, a significant difference between Grades 5 and $9(\mathrm{p}=.034)$.

\subsection{Implicational scaling analysis}

The examination of structures at different times allowed us to follow the development of interlanguage over time, and to reconstruct the rule underlying the occurrence of a given structure. On this basis, it was possible to establish a hierarchy in the succession of structures that emerge in complex verb constructions in the process of acquisition of order within VPs, as deduced from the systematicity observed in the interlanguage of individual learners and also of the different groups (Larsen-Freeman and Long 1991: 110: 'such a display allows us to examine individual performance and the group as a whole'). Our 
learners' development and the hierarchical acquisition of structures are readily presented on an implicational table (Table 4). The information on the implicational table that shows this hierarchy is organized in the following way. From the whole sample, only participants who created empirically relevant contexts in at least one of the structural domains examined here were included. They were rank ordered along the vertical axis as a function of the order in which different structures appear in the learner's interlanguage (irrespective of Grade). A plus (+) indicates that the structure resembled Standard English in adult native speakers. On the contrary, a minus (-) indicates that the structure was 'SEP'. Variability in interlanguage was shown in proportions and no creation of empirically relevant contexts was indicated by a stroke (/). To enhance the visual recognition of the hierarchy, the order in which the learners are presented along the vertical axis has been rearranged so that the structures that are acquired last occupy the left-most position on the table. Also to this aim, the pluses and proportions have been shaded.

As we have just indicated, the table shows a clear hierarchy. The domain where 'Tense + Past Participle' is employed ('Structural Domain 1') turns out to be the most difficult to acquire and it is in this domain that it takes learners longer to produce TL orders. Significantly, when the syntactic structure in this domain has not yet been acquired (that is, the only productive order is 'SEP'), performance in the other domains is analogous: either empirically-relevant contexts are still non-existent, or whenever they are created, the exclusive use of 'SEP' is somehow correlated with orders in 'Modal Auxiliary + Infinitive' ('Structural Domain 4'). This corresponds to Stage 1. On the contrary, by the time the syntactic structure related to the use of 'Tense Auxiliary + Past Participle' is acquired (i.e., only TL orders are systematically used irrespective of accuracy in their use), the syntactic structure related to other auxiliary-verb combinations in other domains has also been acquired and 'SEP' is no longer found. This is the case of 'Tense + Present Participle', where only TL orders are found from the beginning of the acquisition process (Stage 3). The transitional period where the interlanguage grammar of the learners is still optional (i.e., where there is variability in the use of 'SEP' and TL orders) corresponds to the domain where 'Tense Auxiliary + Past Participle' is used. That is, in all other domains where other auxiliaries are used, exclusively TL orders occur systematically (Stage 2). 
Table 4. Implicational Scaling Analysis of 'SEP' in Grades 5, 7, and 9 in different Structural Domains.

\begin{tabular}{|c|c|c|c|c|}
\hline PARTICIPANT & \multirow{2}{*}{$\begin{array}{c}\text { Structural } \\
\text { Domain } \\
\text { ' } 1 \text { ' }\end{array}$} & \multirow{2}{*}{$\begin{array}{c}\text { Structural } \\
\text { Domain } \\
\text { ' } 2 \text { ' }\end{array}$} & \multirow{2}{*}{$\begin{array}{c}\text { Structural } \\
\text { Domain } \\
\text { ' } 3 \text { ' }\end{array}$} & \multirow{2}{*}{$\begin{array}{c}\text { Structural } \\
\text { Domain } \\
\text { ' } 4 \text { ' }\end{array}$} \\
\hline Grades5,7\&9 & & & & \\
\hline $043(\mathrm{G} 7)$ & - & I & I & - \\
\hline 077(G9) & - & I & I & - \\
\hline 003(G5) & - & I & I & I \\
\hline $004(\mathrm{G} 5)$ & - & I & I & I \\
\hline $005(\mathrm{G} 5)$ & - & I & I & I \\
\hline $006(\mathrm{G} 5)$ & - & I & I & I \\
\hline $007(\mathrm{G} 5)$ & - & I & I & I \\
\hline $010(\mathrm{G} 5)$ & - & I & I & I \\
\hline $011(\mathrm{G} 5)$ & - & I & I & I \\
\hline $014(\mathrm{G} 5)$ & - & I & I & I \\
\hline $015(\mathrm{G} 5)$ & - & I & I & I \\
\hline $037(\mathrm{G} 7)$ & - & I & I & I \\
\hline $041(\mathrm{G} 7)$ & - & I & I & I \\
\hline 073(G9) & - & 1 & 1 & 1 \\
\hline $047(\mathrm{G} 7)$ & - & I & I & I \\
\hline $042(\mathrm{G} 7)$ & - & I & I & + \\
\hline 071(G9) & - & + & 1 & 1 \\
\hline $035(\mathrm{G} 7)$ & .50 & 1 & 1 & 1 \\
\hline $036(\mathrm{G} 7)$ & .50 & + & I & 1 \\
\hline 070(G9) & .20 & + & 1 & + \\
\hline 067(G9) & .75 & I & I & 1 \\
\hline 082(G9) & I & + & I & 1 \\
\hline 078(G9) & 1 & 1 & I & + \\
\hline $045(\mathrm{G} 7)$ & 1 & + & I & 1 \\
\hline 001(G5) & + & 1 & 1 & 1 \\
\hline 076(G9) & + & 1 & 1 & 1 \\
\hline 081(G9) & + & 1 & I & 1 \\
\hline $039(\mathrm{G} 7)$ & + & + & 1 & 1 \\
\hline
\end{tabular}

\section{DISCUSSION}

It is now time to recall our research questions. Our first question aimed to resolve whether development can be sequenced into stages in the acquisition of order within VPs in main declarative clauses in English as a third language. The different analyses that have been conducted in order to address this issue have made it possible for us to identify a sequence that consists of three developmental stages. After discussing the qualitative and quantitative differences between these stages, we will discuss the implications that can be 
drawn from them with the purpose of ascertaining which theoretical framework for the analysis of over-time development can better account for these results.

In Stage 1 the first orders that emerge in the interlanguage of our learners correspond to 'SEP'. Indeed, this order was present in all empirically-relevant contexts. At this stage, these contexts were only 'AUX+V[nf]' (Tense Auxiliary + Past Participle), as no other tense or modal auxiliaries had emerged yet. This syntactic behaviour correlated, at the level of morphology, with features that clearly showed that the agreement paradigm was still underdeveloped. In Stage 2 'SEP' is still used productively in the afore-mentioned context, and in fact, it was the most representative order in this context. Notwithstanding, there are two more important sides at this point. The first one is the emergence of tense auxiliaries used with non-finite verb forms other than the past participle (i.e. with the present participle). The second one is the emergence of modal auxiliaries, though these are restricted to only modal auxiliaries that do not express epistemic, deontic or dynamic modality; as a matter of fact, no single instance of these is found in our data (not even in Stage 3).

As it pertains to the orders used in these contexts, there is a markedly different pattern in use depending on the linguistic environment where they occur, that is, depending on structural domain. This suggests that the preference for one order or the other is domainspecific. In addition to context dependency, these results may also be accounted for with another compatible explanation: It might not be a coincidence the fact that all the contexts that emerge at this stage show hardly any incidence of 'SEP'. By the time the learners are ready to create empirically-relevant contexts involving modal auxiliaries, they are also ready to assimilate that 'SEP' is not a possible order in the target language. In Stage 3 although 'SEP' is far from vanished from the learners' interlanguage (as they still represent almost half the percentage of orders in which Tense Auxiliaries are used with a Past Participle), in such contexts these orders are also optionally used in combination with target-like orders. As for the use of modal auxiliaries and of tense auxiliaries in other contexts, little or no change is perceived with respect to the previous stage.

Our second question tried to ascertain whether the transition from one stage to the next is smooth, or whether on the contrary, this transition is sudden and abrupt. The description of the stages reveals information concerning the two most important criteria employed to differentiate stepwise development from gradual development. Our results seem to lend support to the view that grammatical development is both staged and gradual (what seems to invalidate $\mathrm{H} 1$ ). On the one hand, a characteristic that distinguishes Stage 1 performance from Stage 2 performance is the presence of auxiliaries in the interlanguage of our learners, or to be more precise, the categorical presence of a particular auxiliary and the absence of another auxiliary. That is to say, the difference is not so much on the systematicity in structural solutions used in each Stage, but on the emergence in interlanguage of morphological features that must precede the application of certain syntactic rules. This applies also to the characteristic that distinguishes Stage 2 performance from Stage 3 performance.

On the other hand, another characteristic that distinguishes performance across stages is the degree of optionality in interlanguage. As we have seen, this is causally related to the 'increases' and 'decreases' in the occurrence of one or more forms, a process that has been referred to as growth in the literature on first language acquisition (Van Geert 1995: 314). More importantly, from a theoretical point of view, variability is an information carrier 
of the inherent nature of the developmental process. Specifically, Van Dijk and van Geert (2005) claim that variability is both a source of development and an explicit indication of the particular point in time in which there is a developmental transition. The interlanguage grammar of our learners was subject to both inter-learner and intra-learner variability. The co-existence of different structural solutions within groups of learners of the same age is evidence of inter-learner variability. However, this variability is moderate, and the degree to which it happens varies across stages. What is important here is that variability demonstrates that at some point in time learners were capable of producing TL orders, even though they did not do it in all empirically-relevant contexts. The co-existence of different structural solutions in the interlanguage of one and the same learner proves intra-learner variability. It is important to highlight that this type of variability in our data is practically observed only in Stages 2 and 3, and that it represents a relatively small proportion in the whole sample. Hence, in spite of variability, it can be claimed with confidence that in Stage 1 there is no optionality in 'Structural Domain 1'. In the same domain in Stage 2, 'SEP' is, by far, still the predominant order. To a much lesser extent though, in some cases it also co-exists with TL orders, in proportions as high as .80; that is to say, the balance is inclined to a negative equilibrium in favour of 'SEP' that displaces TL orders.

Variability might as well be ultimately related to the distinct patterns obtained for different structural domains. In this sense, we interpret that the availability of different structural solutions to developmental problems that arise when the learner is forced to cope with complex VPs gives way to different sets of variational features. We also interpret the fact that these results are highly context-dependent as evidence for the need to look at a variety of linguistic forms and environments in the analysis of interlanguage development. A logical inference that follows directly from this is two-fold. Firstly, it supports the claim that 'many L2 structures serve as the context for other L2 structures' (Pienemann 1998: 150). In our case, the emergence of morphological features in the learners' interlanguage (such as some of those related to lexical means to express tense or mood) is a prerequisite of and serves as the context for the production of certain complex verb constructions. The description of the development of these morphological features is a by-product that has not been examined in detail in the study reported here because it was not a research goal. However, these linguistic features in the learners' interlanguage are worth mentioning, because they occur in complex verb constructions and have been found to influence the acquisition of order within VPs.

Furthermore, this finding gives ammunition to the claim that development in a linguistic level or language sub-system is a trigger for development in other sub-systems, and reinforces some recent claims. First and foremost, it reinforces de Bot et al.'s (2007: 12) claim that learners 'begin learning grammar when armed at least with the developmental primes of grammatical morphemes and sensitivity to order'. Second, it reinforces the notion of 'carrying capacity', which stands for the state of knowledge that can be reached by the learners' interconnected resources. That is to say, a threshold reached in terms of a relationship between developmental processes taking place at different linguistic levels, which has been referred to as 'Cognitive Ecosystem' Van Geert's (1994: 314) and has been related to degree of language exposure and to maturity. The morphological features aforementioned are good indicators of general development in morphosyntax, and future research on third language 
acquisition should attend to their over-time development and the sequencing of the stages in their acquisition. Secondly, these results not only shed light on the intrinsic processes in the acquisition of order within VPs, but they also underscore the vulnerability of syntactic domains (e.g. Bohnacker, 2007; Müller, 2003) and the theoretical and methodological relevance of the simultaneous analysis of a number of linguistic environments.

In this regard, another reading of our findings is that optionality or variability in the interlanguage grammar of our learners may be constrained by input. In particular, it seems that the use of structures in the area of morphosyntax is highly sensitive to frequency of occurrence (Ellis 2002). In order to explain how exactly the relative frequency of patterns in the input affect acquisition, it is necessary to pay attention to the fact the highest productivity of and systematicity in the use of 'SEP' in our data occurred in a particular linguistic environment (i.e. 'Structural Domain 1'). The assertion that 'SEP' is ruled out from 'Structural Domain 2' in all Stages may not be a matter of chance. As we have suggested in section 3.3.1, German does not mark progressive aspect, and there is no equivalent to English present continuous in the verb paradigm of this language. It is our interpretation that the perceptual salience of this typological difference might be decisive in the establishment of form-function mappings and of one-to-one relations in the target language, and that it could help to figure out why no 'SEP' orders appear in that linguistic environment. This lends support to the claim that the relative frequency of patterns in the input affects the acquisition of order within VPs not as much as a function of their 'token' frequency, but of the 'type' frequency (Bybee 1995; Bybee and Hopper 2001).

However, in this interpretation 'token' frequency would also play a role. Previous studies within the BAF project with another population sample (e.g., Muñoz and Sanchez $2003^{10}$ ) have found that the choice of verb tense by EFL learners without knowledge of German is different from that reported here. In fact, the learners in that other sample used uninflected forms initially, and these were increasingly replaced by forms in present continuous (i.e., present participle forms with or without auxiliary) and later also by forms in present simple and past simple. This difference might be explained by two key pieces of evidence. First, the German equivalent of English present perfect tense (i.e., 'Das Perfekt', see Klosa et al. 1998 ) is the default choice employed to make reference to 'past' as a relational concept. Nonetheless, in contrast to English, the central use of this secondary tense is not only used to locate the situation or part of it in a past time preceding the moment of speaking or to refer to the current relevance of past events (Huddleston and Pullum, 2006), but it is expanded

\footnotetext{
10 Muñoz and Sanchez (2003) investigated the acquisition order of 8 morphemes (Progressive -ing, Plural -s, Singular copula, Progressive auxiliary, Article, Irregular past, Simple past, and Third persona singular) in six formally instructed groups. These groups were subdivided into two cohorts depending on starting age (i.e., 8 and 11) and tested after 200, 416 and 726 hours of instruction, and data was gathered using the same Story Telling Task that we have used in the present study and also data coming from a Semi-structured Interview. Following Pica's (1983) methodology, SOC percentages (i.e., Suppliance in Obligatory Contexts) were calculated and the rank orders found for the groups investigated were correlated with Krashen's natural order, and with Pica's 'Instruction only', 'Naturalistic' and 'Mixed Groups'. The results yielded high significant correlations between the rank orders in the groups they investigated and those reported in prior research. Their findings suggested that that Regular past and Third person singular were the latest morpheme to emerge in the learners' interlanguage, which is consonant with acquisition sequences that have been found in other studies in morpheme acquisition in English as a foreign language with learners from different background languages (e.g., Dulay and Burt, 1974; Krashen et al., 1978; Pica, 1983).
} 
to describe as well situations that in English would be expressed through a primary tense (i.e., the preterite). Second, as a consequence of this, if compared with other tenses, the secondary tense may be more frequent in the input learners receive in their L2.

In sum, these results are supportive of a view of over-time interlanguage development that integrates 'stages' (i.e. movement from one solution to another) and 'continua' (i.e. co-existence of different solutions into a single whole). Furthermore, our data corroborates that there are periods of co-existence between forms and that they might cover more or less long time periods. However, it is absolutely discernible whether the pattern does not match any TL rule, and what is more, apart from periods where "neither the L1 nor the L2 item is clearly dominant" (Sharwood Smith and Truscott, 2005: 235), the data demonstrates the existence of clearly definable stages where one language other than the TL is dominant (Stage 1). But these results and the developmental sequence identified here are valid for the lifespan and circumstances of the population sample participating in this study, so further research should manipulate these circumstances and find out whether the same or different results are yielded. After all, we cannot forget that "minimal structural growth" is conditioned by factors external to the learner, such as spatial environment, time spent in this environment and input received from it. In this sense, de Bot et al. (2007) propose the hypothesis that the starting point and the learning rate might yield different patterns in development, as development is seen as an iterative process. Three specific directions for future research are outlined in terms of study replication. A promising proposal is the replication of the study under different exposure and cognitive conditions. The study presented here focuses on acquisition by learners whose age range is between 10 and 15 . Research in the field would benefit from investigation into other lifespans with learners younger and older than those analyzed here, and with different extents and intensities of input through formal instruction. Another proposal is the replication of the study using a different (i.e., written) modality of the same elicitation technique. This would eventually allow for validation of the hierarchy found, and for observing the likelihood of task effects. Finally, replication of the study should expand the scope of the targeted linguistic feature analyzed here to other features, as for example the acquisition of order within VPs in embedded clauses. Notwithstanding, in spite of the variability that can be found in these unstable external conditionings on 'time' and 'space', we must follow Ellis' 2007 recommendation that we may not want to lose track of the systematicity that can without doubt be detected if the researcher decides to concentrate on the bunch of leafs, blossom and bole in order not to 'lose sight of the word for the tree' (p. 29); or among similar lines, de Bot et al.'s (2007: 7) recommendation not to 'regard real-life messy facts as 'noise' but as part of the 'sound' you get in real life'

\section{REFERENCES}

Andersen, R. 1978. 'An implicational model for second language research.' Language Learning 28/2: 221-282.

ANDERSEN, R. 1984. 'The one-to-one principle of interlanguage construction.' Language Learning 34/4: 77-95. 
BAHNS, J. 1983. 'On acquisitional criteria.' IRAL 21/1: 57-67.

BARTNING, I. AND S. SCHLYTER. 2004. 'Itinéraires acquisitionnels et stades de dévelopmmement en français $\mathrm{L}_{2}$.' French Language Studies 14/ 3: 261-299.

BECK, M. 1998. 'L2 acquisition and obligatory head movement.' Studies in Second Language Acquisition 20/3: 311-148.

BoL, G. 1995. 'Implicational scaling in child language acquisition: the order of production of Dutch verb constructions' in Verrips, M. and F. Wijnen (eds.): Papers from The Dutch-German Colloquium on Language Acquisition, Amsterdam Series in Child Language Development, 3, Amsterdam: Institute for General Linguistics, pp. 1-13.

Bohnacker, U. 2007. 'On the "Vulnerability" of Syntactic Domains in Swedish and German.’ Language Acquisition 14/1: 31-53.

BybeE, J. 1995. 'Regular Morphology and the lexicon.' Language and Cognitive Processes 10/5: 425-455.

Bybee, D. And J. Hopper. 2001. Frequency and the Emergence of Linguistic Structure. Amsterdam: John Benjamins.

Carroll, M., J. Murcia-Serra, M. Watorek, and A. Bendiscioli. 2000. 'The relevance of information organization to second language acquisition studies: The descriptive discourse of advanced adult learners of German.' Studies in Second Language Acquisition 22/3: 441-466.

Clahsen, H. 1985. 'Profiling second language development: A procedure for assessing L2 proficiency' in Hyltenstam, K. and M. Pienemann (eds.): Modelling and Assessing Second Language Acquisition. Clevedon: Multilingual Matters, pp. 283-331.

Clahsen, H., and P. Muysken. 1989 'The UG paradox in L2 acquisition'. Second Language Research 5/1: 93-119.

CORDER, S. 1978. 'Language-learner language' in Richards, J. (ed.): Understanding Second and Foreign Language Learning. Rowley, Mass.: Newbury House.

DeBot, D., W. Lowie AND M. Verspoor. 2007. 'A Dynamic Systems Theory approach to second language acquisition.' Bilingualism: Language and Cognition 10/1: 7-21.

DeCAMP, D. 1973. 'Implicational scales and sociolinguistic linearity.' Linguistics 73/1: $30-43$.

DitTMAR, N. 1980. 'Ordering adult learners according to language abilities' in Felix, S. (ed.): Second Language Development. Tübingen: Gunther Narr, pp. 205-31.

Dulay, H., AND BuRT, M. 1974. 'Natural sequences in child second language acquisition.' Language Learning 24/1: 37-53.

Dulay, H., AND Burt, M. 1977. 'Remarks on creativitiy in language acquisition' in Burt, M. H. Dulay, and M. Finocchiaro (eds.): Viewpoints on English as a second language. New York: Regents, pp. 95-126. 
Dulay, H., M., Burt, and S. Krashen. 1982. Language Two. New York: Oxford University Press.

ElLis, N. 2002. 'Frequency effects in language processing. A review with implications for theories of implicit and explicit language acquisition'. Studies in Second Language Acquisition 24/2: 143-188.

Ellis, N. 2007. 'Dynamic systems and SLA: The wood and the trees.' Bilingualism: Language and Cognition 10/1: 23-25.

Ellis, R. 1989. Understanding Second Language Acquisition. Oxford: Oxford University Press.

ElLIS, R. 1994. 'Developmental patterns: order and sequence in second language acquisition' in Ellis, R.: The Study of Second Language Acquisition: Oxford: Oxford University Press.

Elman, J., E. Bates, M. Johnson, A. Karmiloff-Smith, D. Parisi, and K. Plunkett. 1996. Rethinking innateness: A connectionist perspective on development. Cambridge, MA.: MIT Press.

EuBANK, L. 1994. 'Towards an Explanation for the Late Acquisition of Agreement in L2.' Second Language Research 10/1: 84-93.

GAss, S. 1980. 'An investigation of syntactic transfer in adult second language learners' in Scarcella, R. and S. Krashen (eds.): Research in Second Language Acquisition. Rowely, Mass.,: Newbury House, pp. 132-141.

Goldschneider, J., And R. DeKeyser. 2001. 'Explaining the „Natural Order of L2 Morpheme Acquisition” in English: A Meta-analysis of Multiple Determinants.' Language Learning 51/1: 1-50.

Greenbaum, S., And R. Quirk. 1990. A student's grammar of the English language. Essex: Longman. 2n edition (1993).

GutTman, L. 1944. 'A basis for scaling qualitative data.' American Sociological Review 9/1: 139-150.

Herdina, P., And U. Jessner. 2002. A Dynamic Model of Multilingualism. Perspectives of change in Psycholinguistics. Clevedon: Multilingual Matters.

Hopp, H. 2003. Syntax and its Interfaces in L2 Grammars- Situating L1 effects. Paper presented at the Proceedings of GALA Conference.

Huddleston, R., And G. Pullum. 2005. A student's introduction to English Grammar. Cambridge: Cambridge University Press. 2n Edition (2006).

Hyltenstam, K. 1977. 'Implicational patterns in interlanguage syntax variation.' Language Learning 27/2: 383-411.

Jordens, P. 1988. 'The acquisition of word order in L2 Dutch and German' in Jordens, P., and J. Lallemann (eds.): Language Development. Dordrecht: Foris, pp. 149-80. 
Kormos, J. 2007. Developing the discourse-pragmatics/syntax interface in second language acquisition: Processability Theory approaches- Discussion.' Paper presented at the $17^{\text {th }}$ European Second Language Acquisition Conference: Newcasttle: England.

Krashen, S., J. Butler, R. Birnbaum, and J. Robertson. (1978). 'Two studies in language acquisition and language learning.' ITL: Review of Applied Linguistics 39-40: 73-92.

Klosa, A., W. Scholze-Stubenrecht, and M. Wermke. 1998. Duden. Die Grammatik der deutschen Gegenwartssprache. Mannheim: Dudenverlag.

LARSEN-FrEEMAN, D. 1997. 'Chaos/ complexity science and second language acquisition’. Applied Linguistics 18/2: 141-65.

Larsen-Freeman, D. And M Long..1991. An Introduction to Second Language Acquisition Research. New York: Longman.

Lightвown, P. 1983. 'Exploring Relationships between Developmental and Instructional Sequences in L2 Acquisition' in Seliger, H. and M. Long (eds.): Classroom Oriented Research in Second Language Acquisition. Cambridge: Newbury House, pp. 217-245.

MacLaughlin, B. 1990. 'Restructuring.' Applied Linguistics 11/2: 113-28.

MacWhinney, B. 1997. 'Second language acquisition and the competition model' in De Groot, A., and J. Kroll (eds.): Tutorials in bilingualism: Psycholinguistic perspectives. Mahway, NJ: Lawrence Erlbaum Associates, pp. 113-42.

Möhring, A., AND J. Meisel. 2003. 'The Verb-Object parameter in simultaneous and successive acquisition of bilingualism' in Müller, N. (ed.), pp. 295-334.

Müller, N. 2003. (In)vulnerable Domains in Multilingualism. Amsterdam: John Benjamins.

MuÑoz, C. 2006. Age and the rate of foreign language learning. Clevedon: Multilingual Matters.

Muñoz, C. And L. SAnchez. 2003. 'Morpheme Development in Two Groups of EFL Learners' in Rodriguez, A., D. Pastor, and P. Pardo (eds.) 2004: Proceedings of the 27th International AEDEAN Conference. CD-ROM. Salamanca: English Philology Department.

NEMSER, W. 1971. 'Approximative systems of foreign language learners.' International Review of Applied Linguistics 9/2: 115-123.

Pallotti, G. 2007. 'An Operational Definition of the Emergence Criterion.' Applied Linguistics 28/3, 361-82.

PicA, T. 1983. 'Adult acquisition of English as a second language under different conditions of exposure.' Language Learning 33/4: 465-497. 
Pienemann, M. (1998) Language processing and second language development. Amsterdam: John Benjamins.

Platt, J. 1977. 'English Past Tense Acquisition by Singaporeans- Implicational Scaling versus Groups Averages of Marked Form.' ILT, International Review of Applied Linguistics 38/1: 63-83.

Author. 2007a. English after German: Developmental Sequences in the Formal Acquisition of Verb Placement in English as a Third Language. Paper presented at the $17^{\text {th }}$ European Second Language Association Conference: Newcastle: England.

Author. 2007b. Task Modality and Developmental Sequences in the Acquisition of Morphosyntactic features in EFL. Paper presented at the Thirtieth Second Language Research Forum. Illinois (Urbana-Champaign): United States.

Schumann, J. 1979. 'The acquisition of English negation by speakers of Spanish: a review of the literature' in Andersen, R. (ed.): The Acquisition and Use of Spanish and English as First and Second Languages. Washington, D.C.: TESOL, pp. 3.32.

Selinker, L. 1972. 'Interlanguage.' International Review of Applied Linguistics 10/3: 209-230.

Selinker, L., M. Swain, And G. Dumas. 1975. 'The interlanguage hypothesis extended to children.' Language Learning 25/1 :139-152.

Sharwood Smith, M. 2004. 'In two minds about grammar: On the interaction of linguistics and metalinguistic knowledge in performance.' Transactions of the Philological Society 102/2: 225-280.

Sharwood Smith, M., And J. Truscott. 2005. 'Stages or Continua in Second Language Acquisition: A MOGUL Solution.’ Applied Linguistics 26/2: 219-240.

Sorace, A. 2000. 'Syntactic optionality in non-native grammars.' Second Language Research 16/2: 93-102.

StUtTERHeim, vON C. 2003. 'Linguistic structure and information organization: The case of very advanced learners.' EUROSLA Yearbook, vol. 3. Amsterdam: John Benjamins, pp. 183-206.

Truscott, J., And M. Sharwood Smith. 2004. 'Acquisition by processing: A modular approach to language development.' Bilingualism: Language and Cognition 7/ 1: $1-20$.

White, L. 1991. Second Language Acquisition and Universal Grammar. Cambridge: Cambridge University Press.

VAn Dijk, M. And P. VAn GeERT. 2005. 'Disentangling behavior in early child develoment: Interpretability of early child language and the problem of filler sylables and growing utterance length.' Infant Behavior and Development 28/1: 99-117.

VAn Geert, P. 1995. 'Dimensions of change: A semantic and mathematical analysis of learning and development.' Human Development 38/6: 322-331. 
VainikKa, A. And M. Young-Scholten. 1994. 'Direct access to X'-Theory. Evidence from Korean and Turkish adult learners of German' in Hoekstra, T. and B. Schwartz (eds.): Language Acquisition Studies in Generative Grammar. Amsterdam: John Benjamins.

\section{ACKNOWLEDGEMENTS}

I am grateful to Scott Jarvis and also to Terence Odlin for their support and for their insightful comments on the analysis of the data. The work presented here is part of two larger projects on the Age Factor (i.e. BAF and BAFIA) coordinated by Carmen Muñoz. These projects are funded by grant FFI2010-21478 (Spanish Ministry of Education and Science), and a grant to the author (2005 BE 00687 by the Agency of University Financial Management and Research).

\section{APPENDIX. 'THE DOG STORY'}
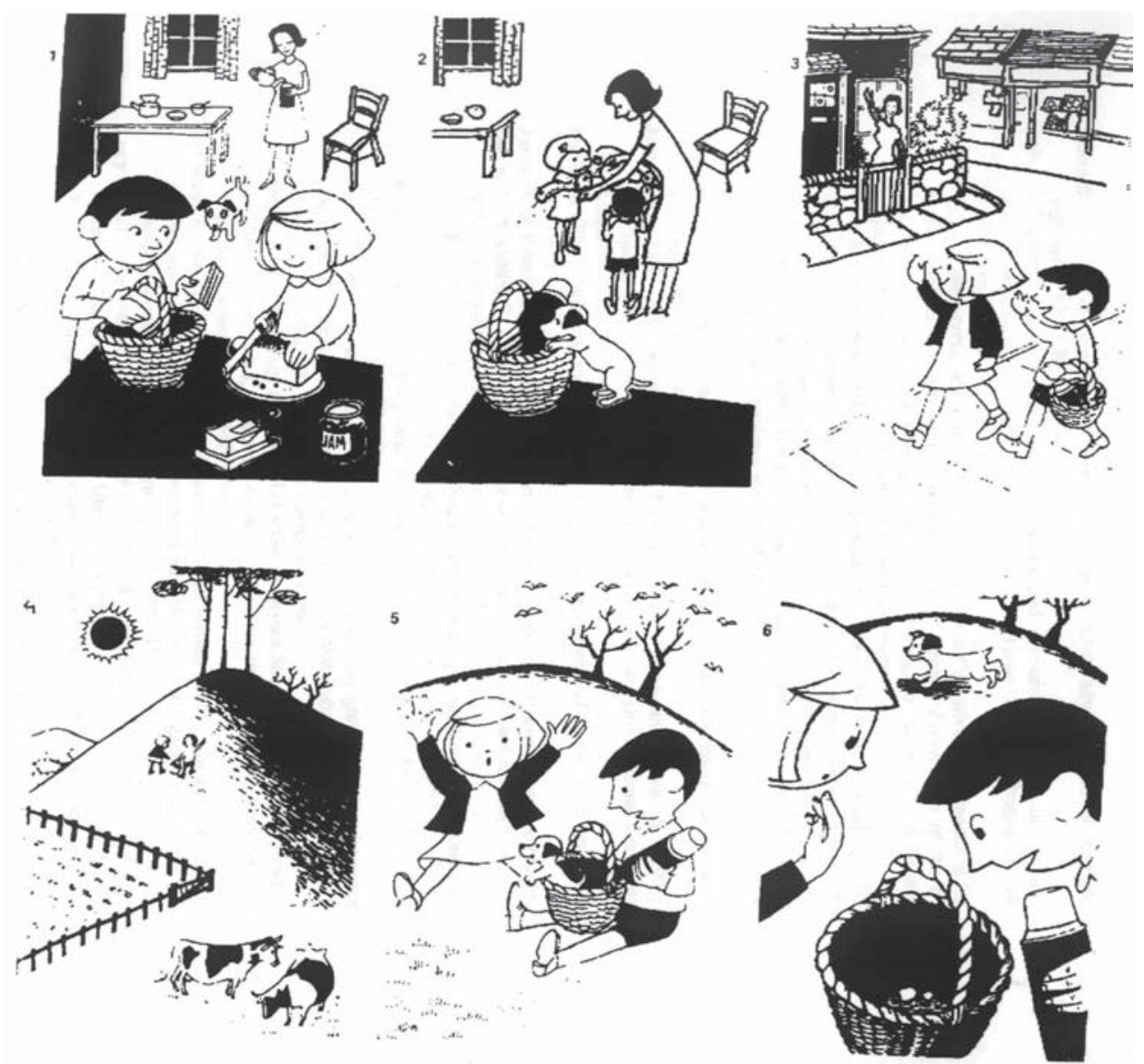